Supporting Information for:

\title{
Reactivity studies of Cationic Au(III) difluorides supported by $\mathrm{N}-1$ igands
}

Lachlan Sharp-Bucknall, Lachlan Barwise, Jason Bennetts, Mohammad Albayer and Jason L. Dutton*

Department of Chemistry and Physics, La Trobe Institute for Molecular Science, La Trobe University, Melbourne, Victoria, Australia, 3086 


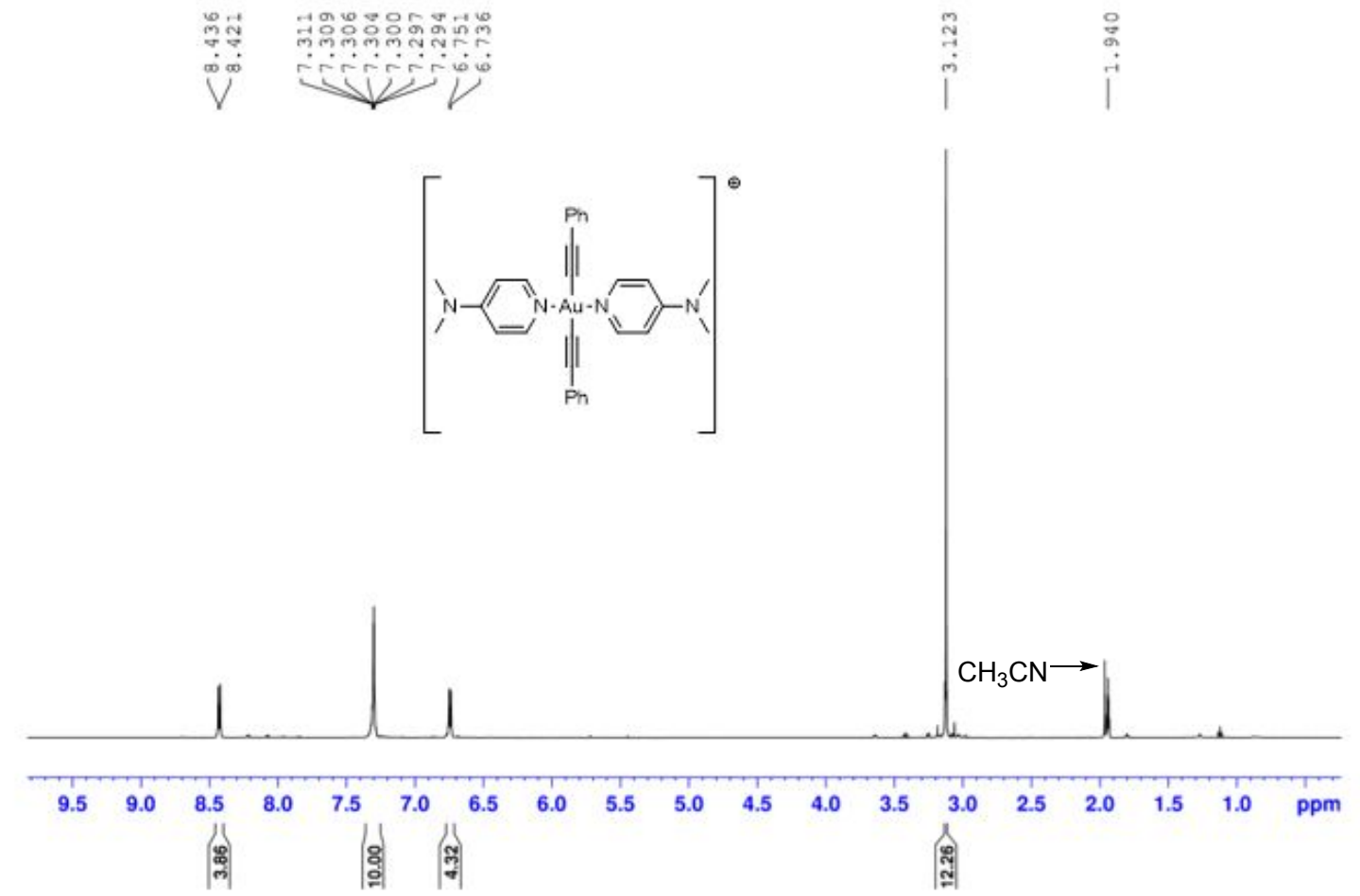

Figure S1. ${ }^{1} \mathrm{H}$ NMR of 11DMAP.

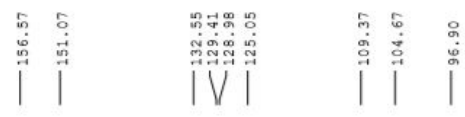

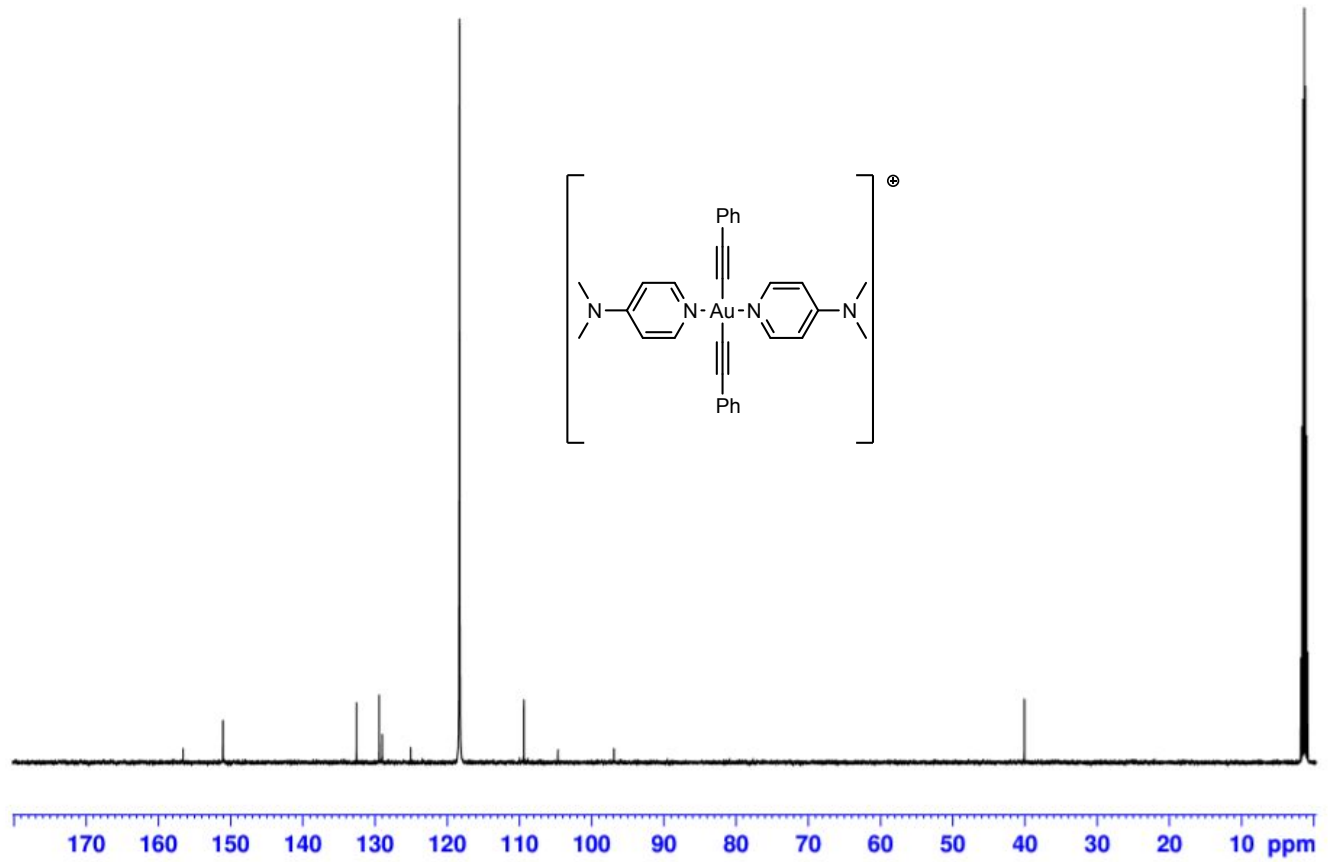


Figure S2. ${ }^{13} \mathrm{C}$ NMR of 11DMAP.

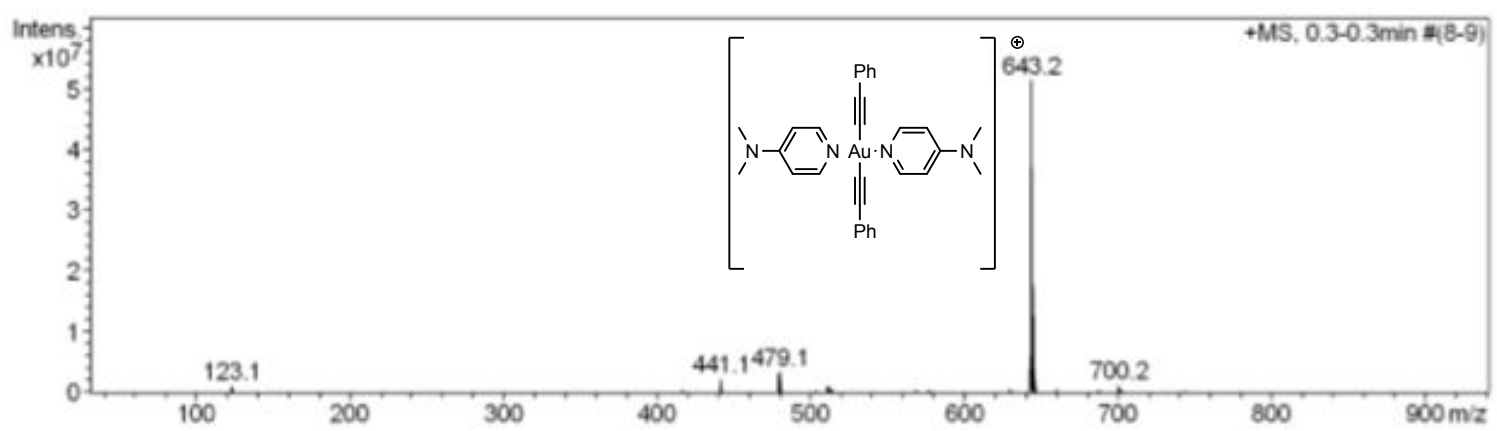

Figure S3. ESI-MS of 11DMAP.
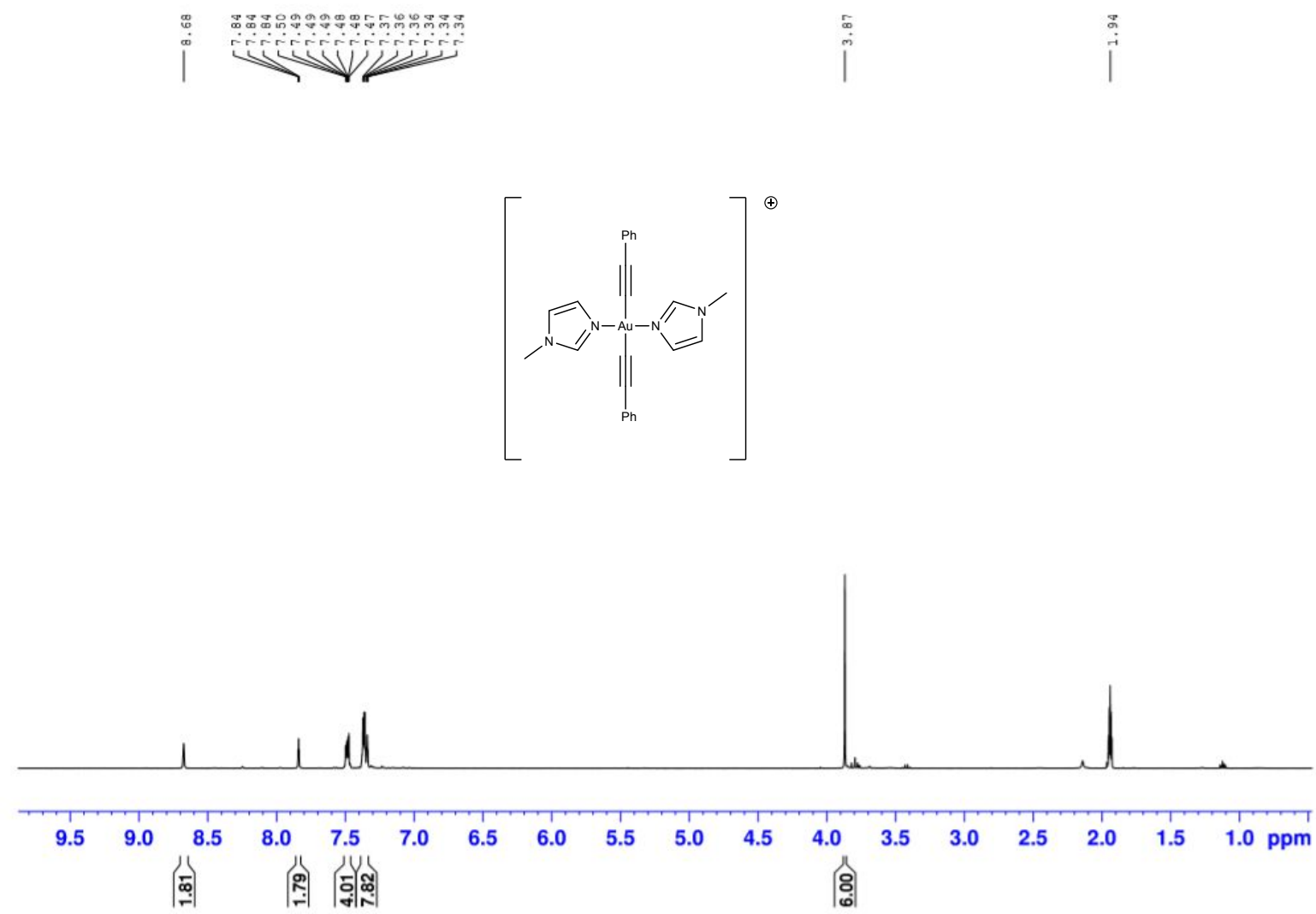

Figure S4. ${ }^{1} \mathrm{H}$ NMR for 11IM. 


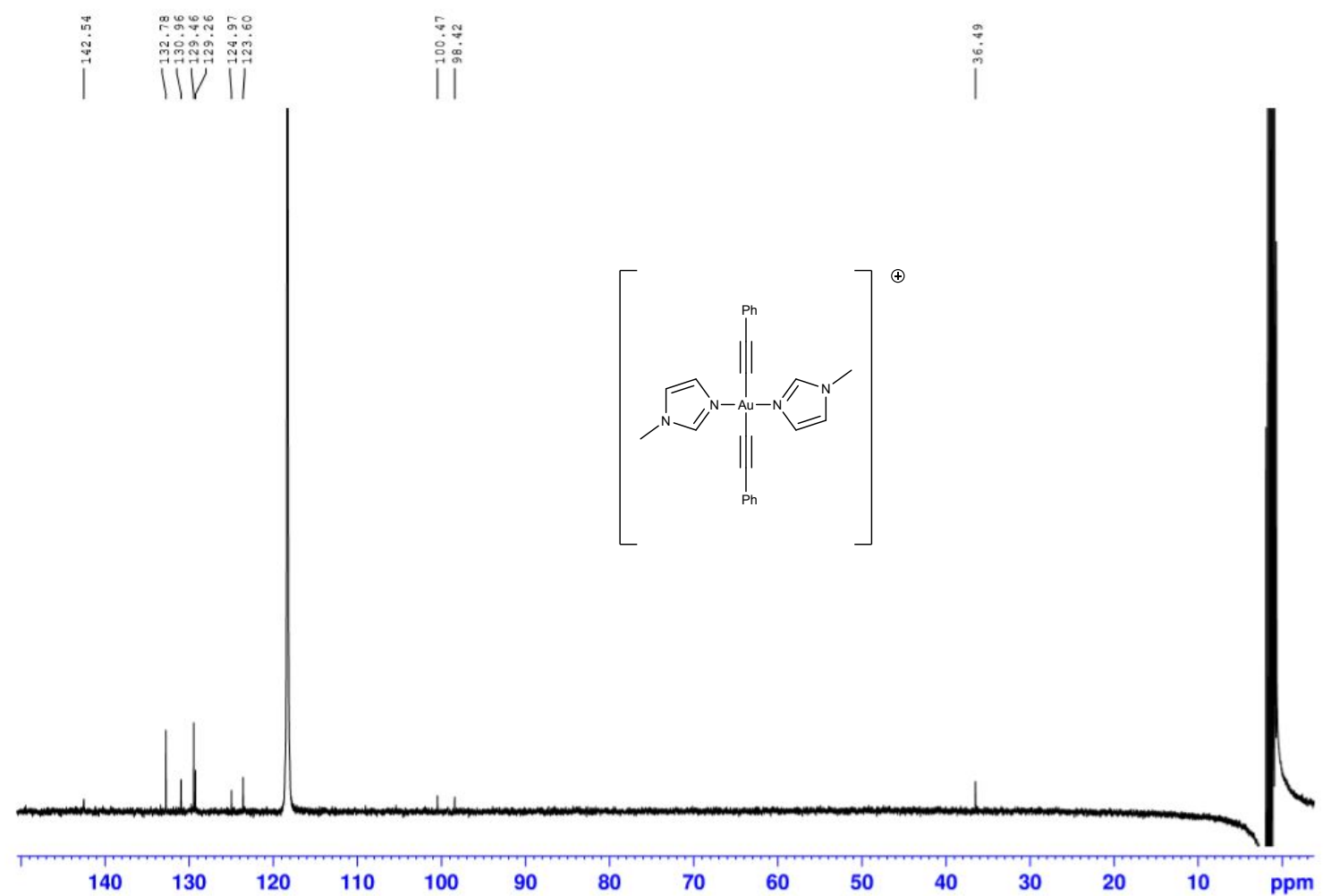

Figure S5. ${ }^{13} \mathrm{C}$ NMR for 11IM.

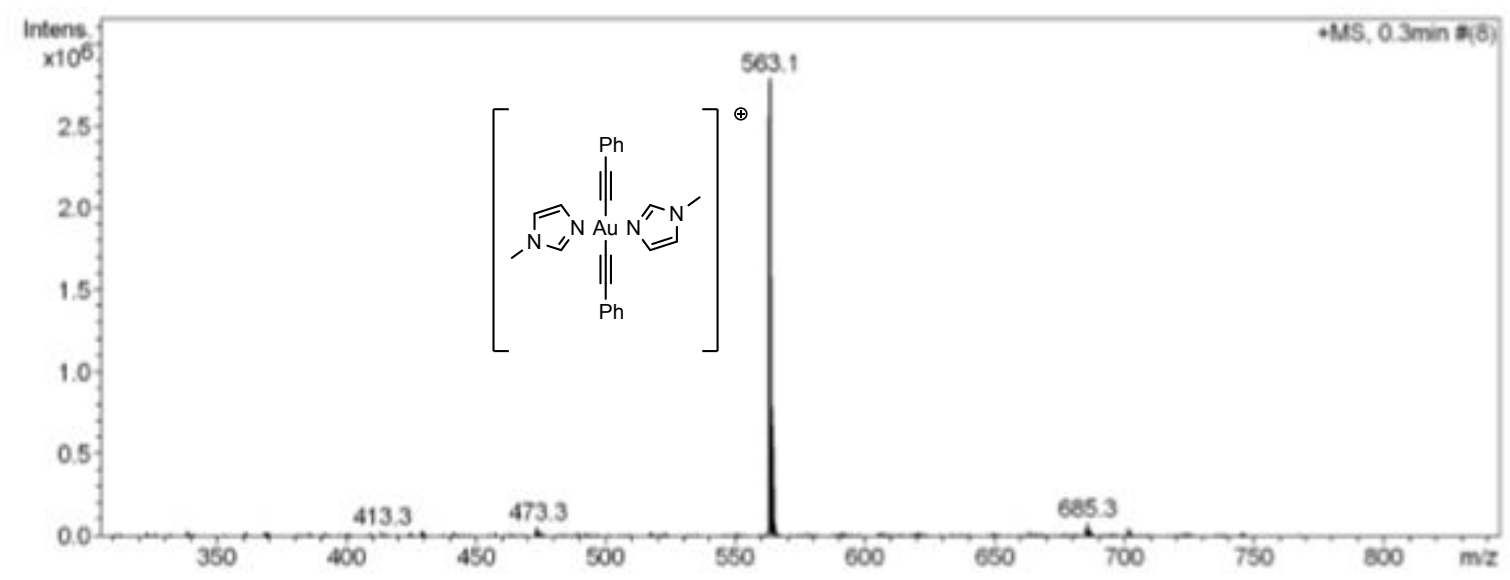

Figure S6. ESI-MS of 11IM. 


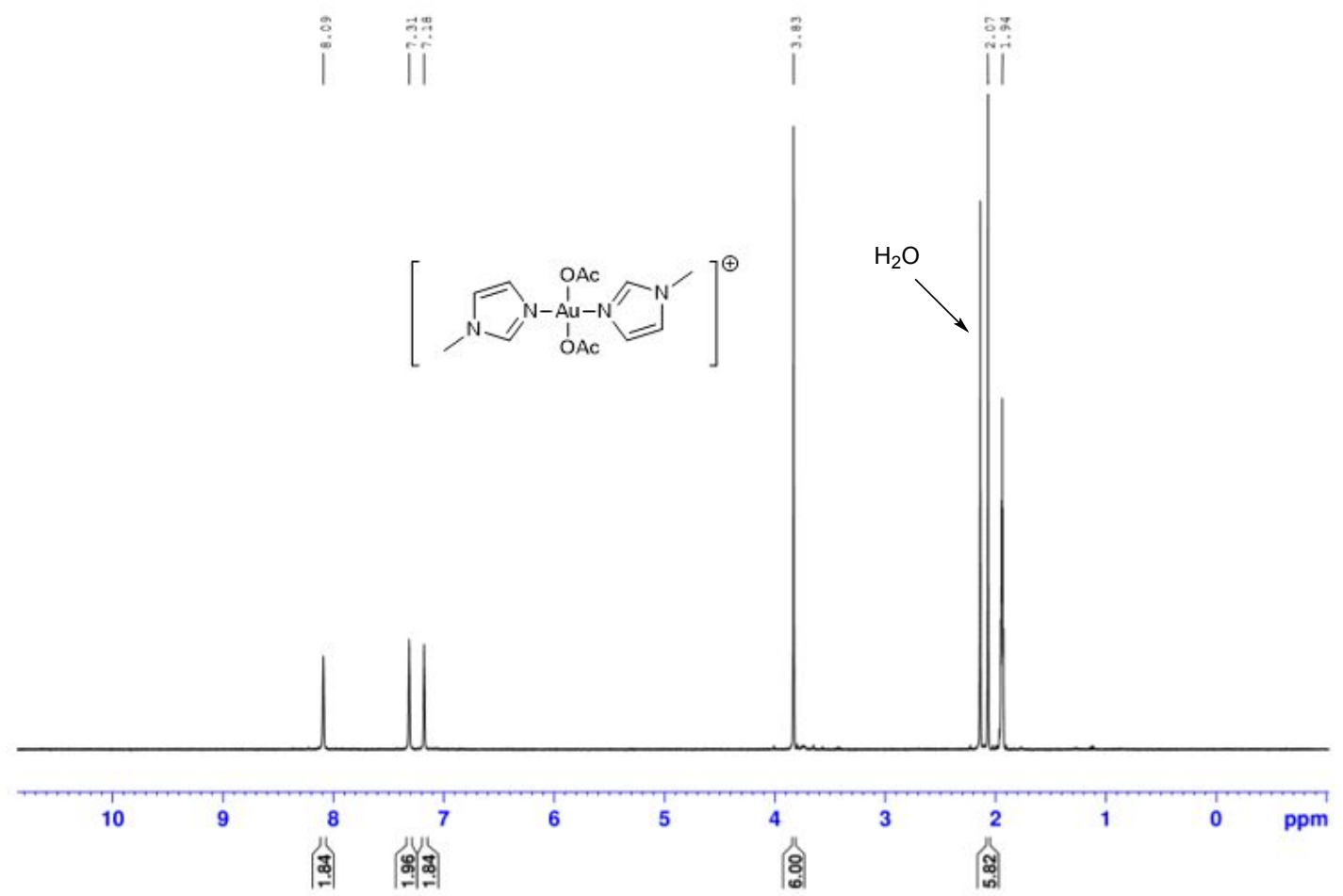

Figure S7. ${ }^{1} \mathrm{H}$ NMR of 12IM.

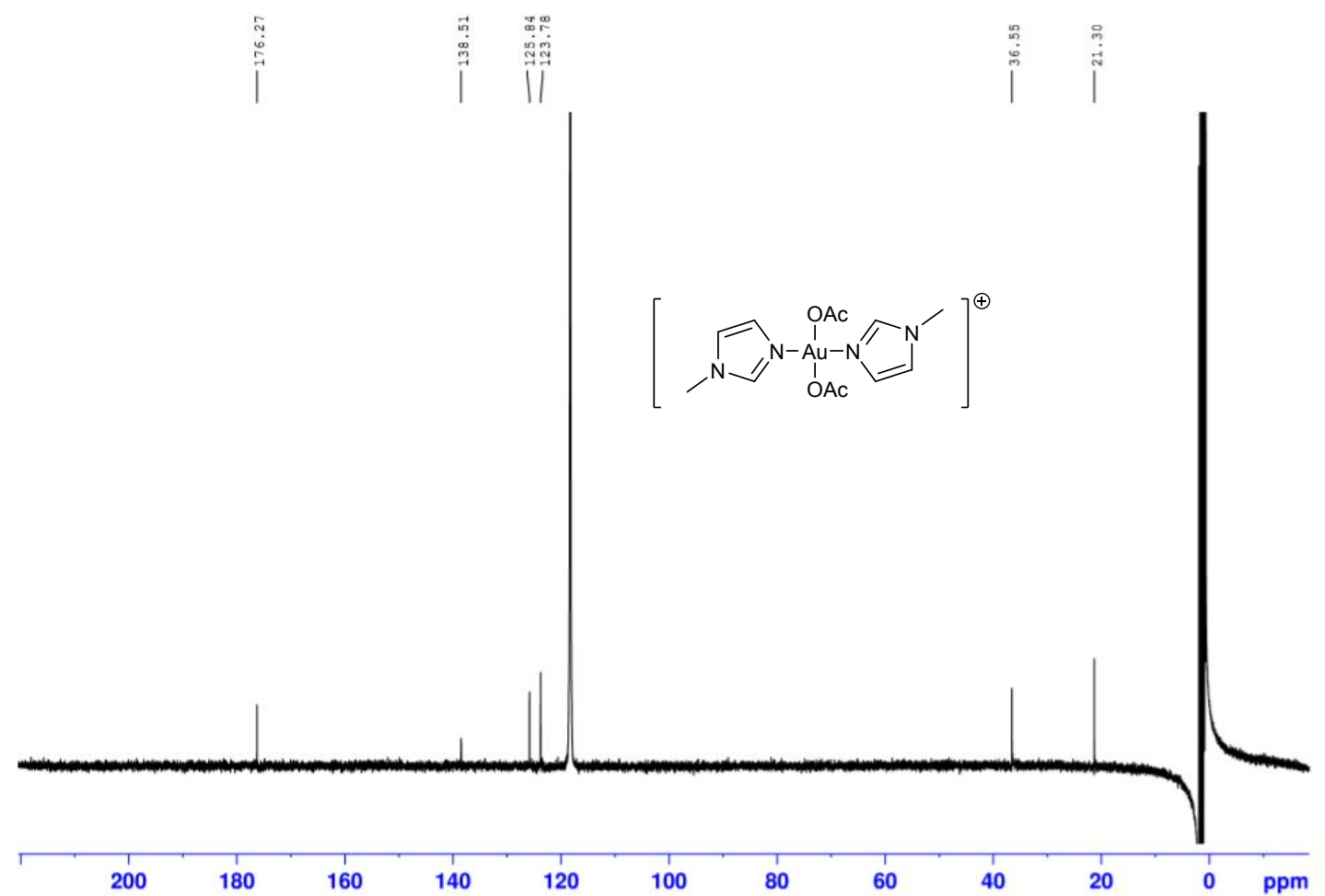

Figure S8. ${ }^{13} \mathrm{C}$ NMR of 12IM. 


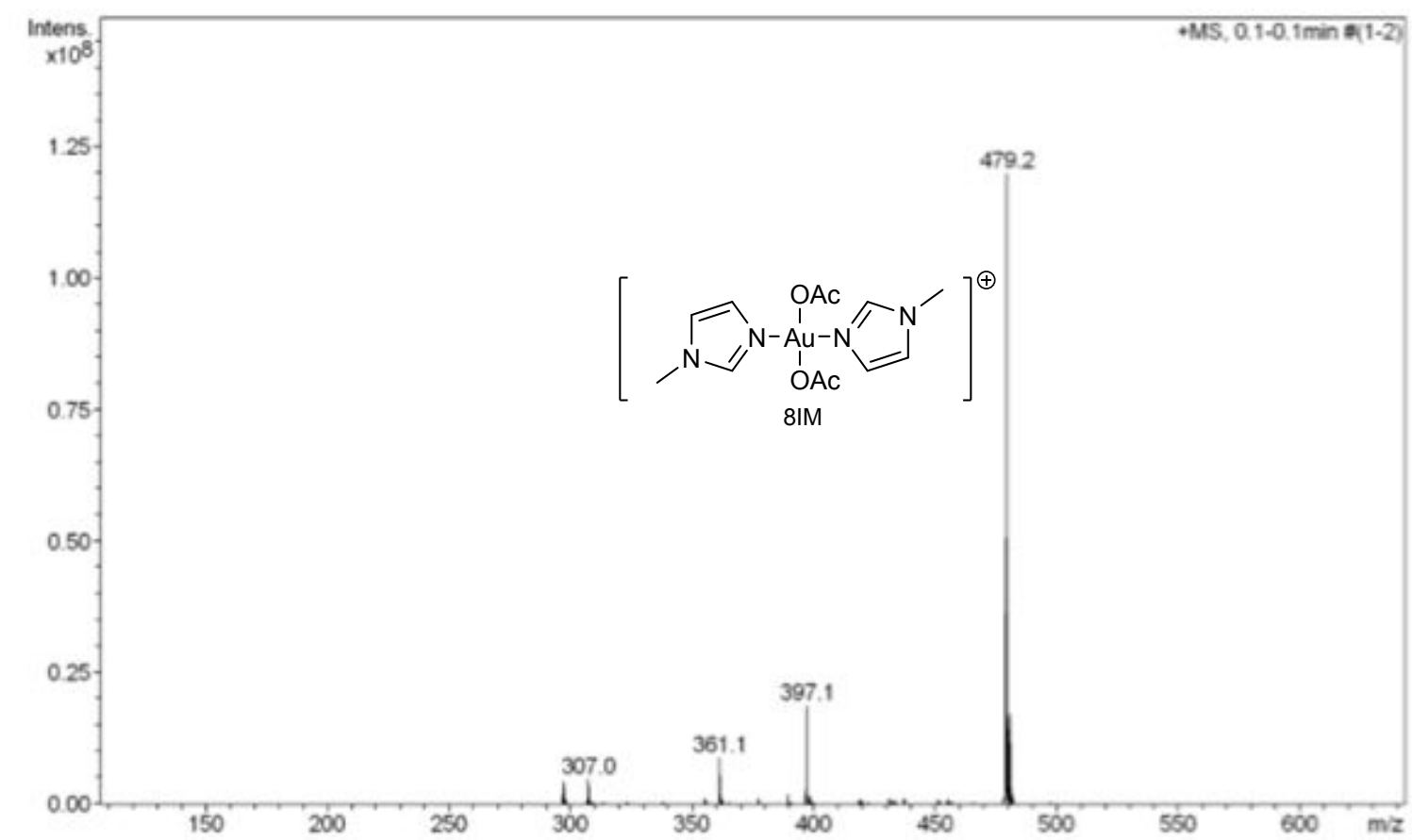

Figure S9. ESI-MS of 12IM.

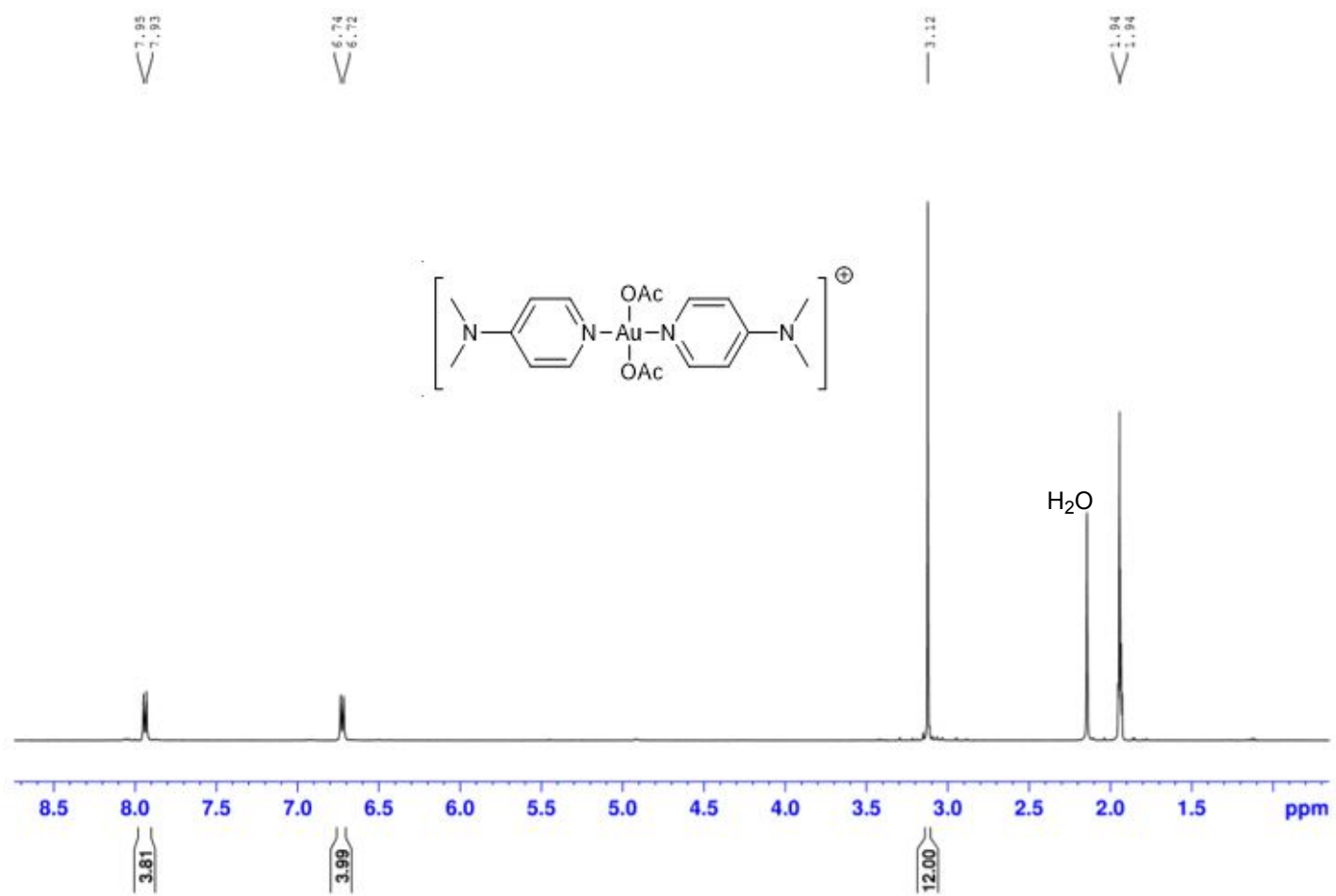

Figure S10. ${ }^{1} \mathrm{H}$ NMR of 12DMAP. 


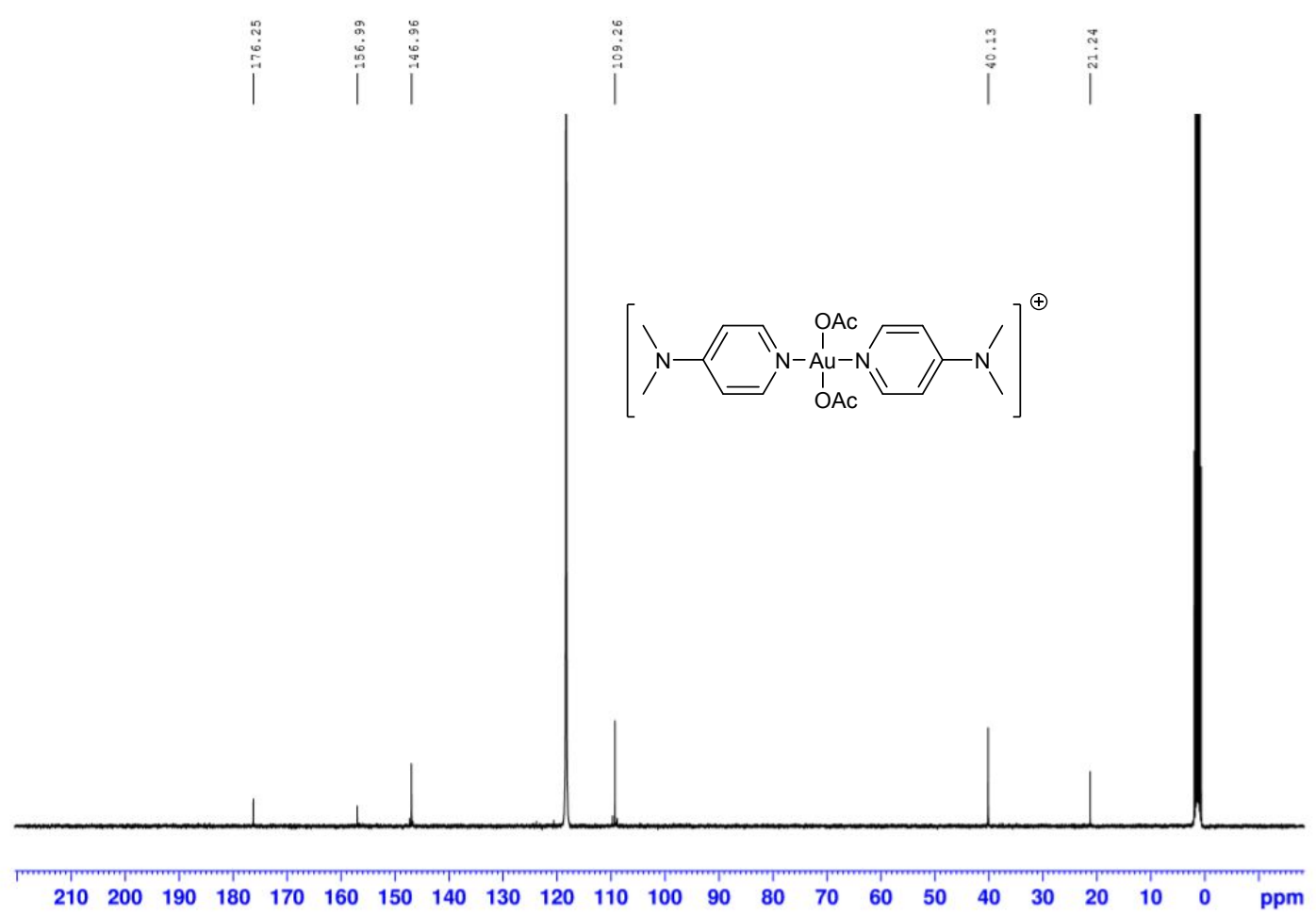

Figure S11. ${ }^{13} \mathrm{C}$ NMR of 12DMAP.

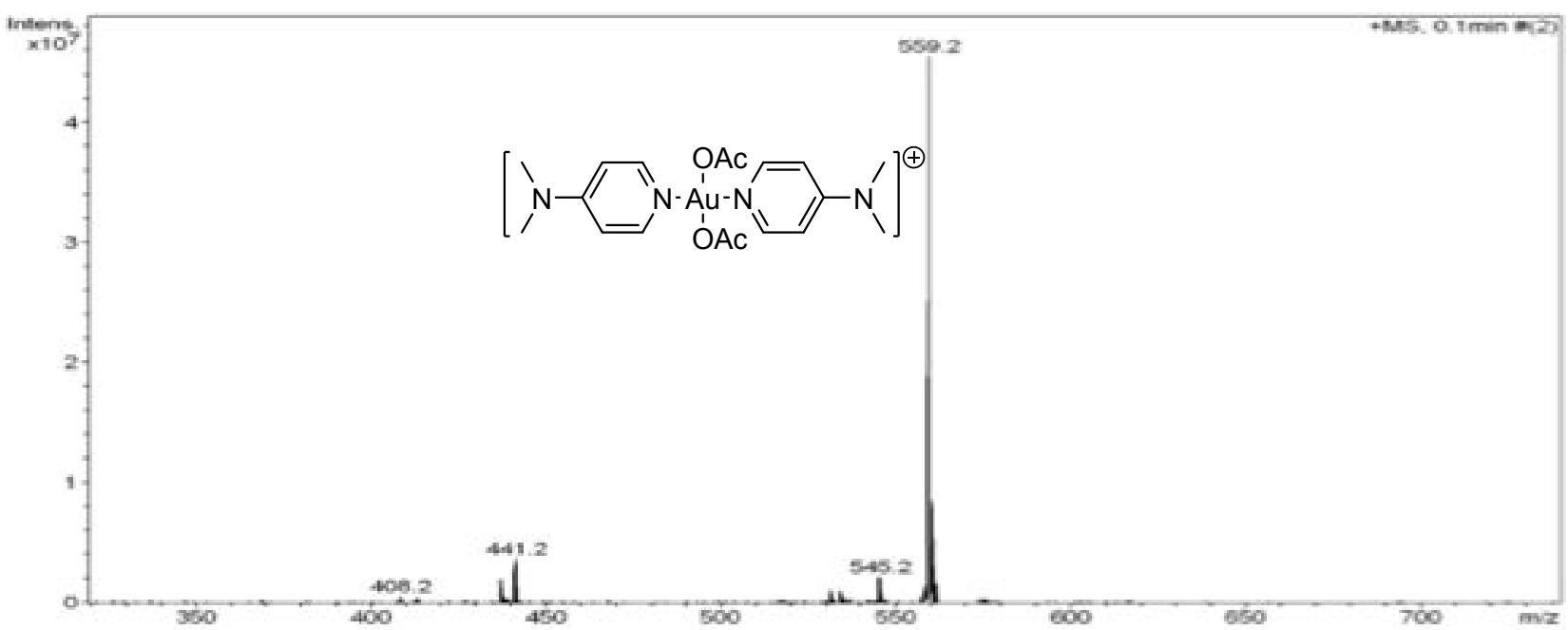

Figure S12. ESI-MS of 12DMAP. 


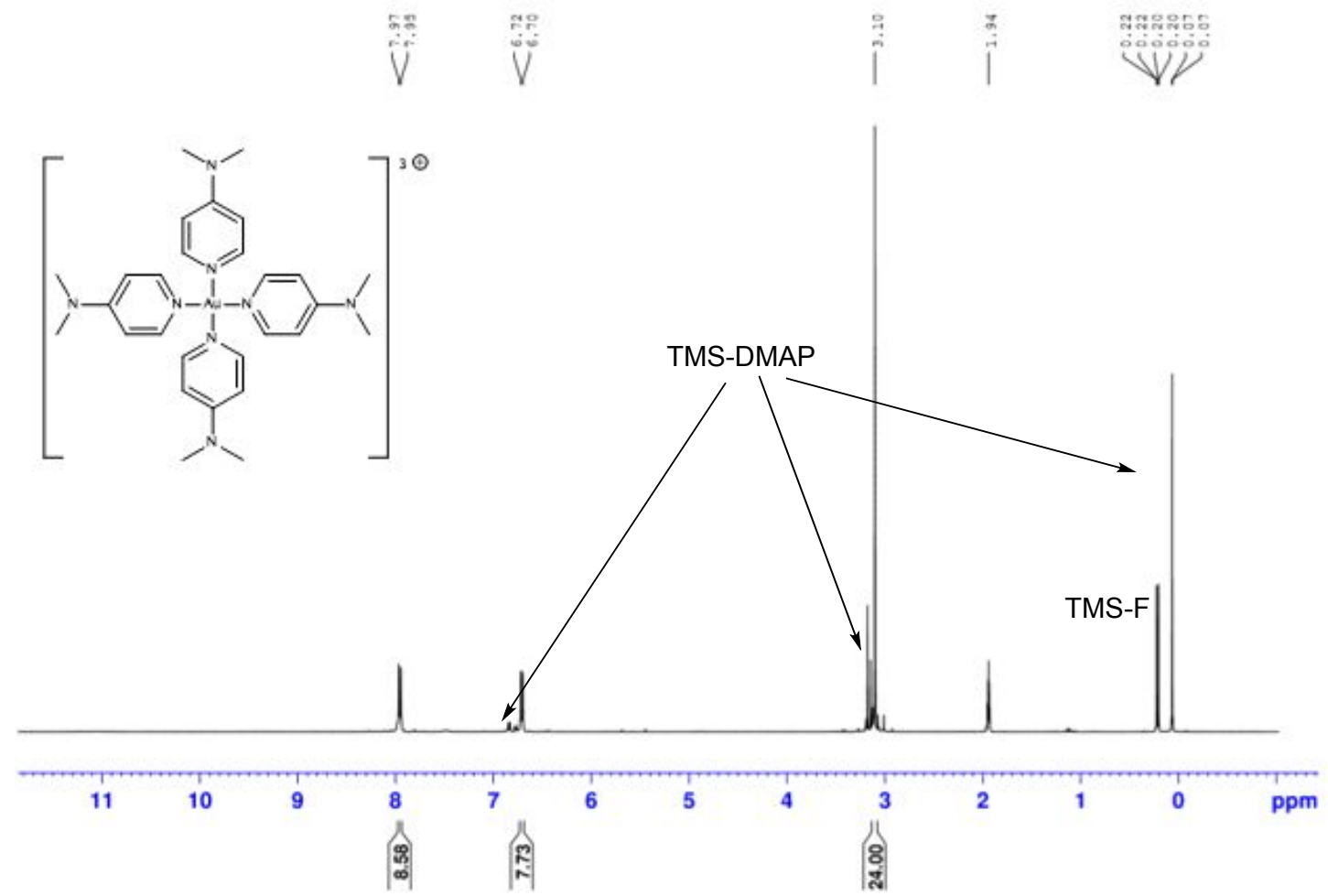

Figure S13. In situ ${ }^{1} \mathrm{H}$ NMR of $\mathbf{8 N M e}_{2}$ from reaction between 6DMAP and $7 \mathrm{NMe}_{2}$.

VัV VัV

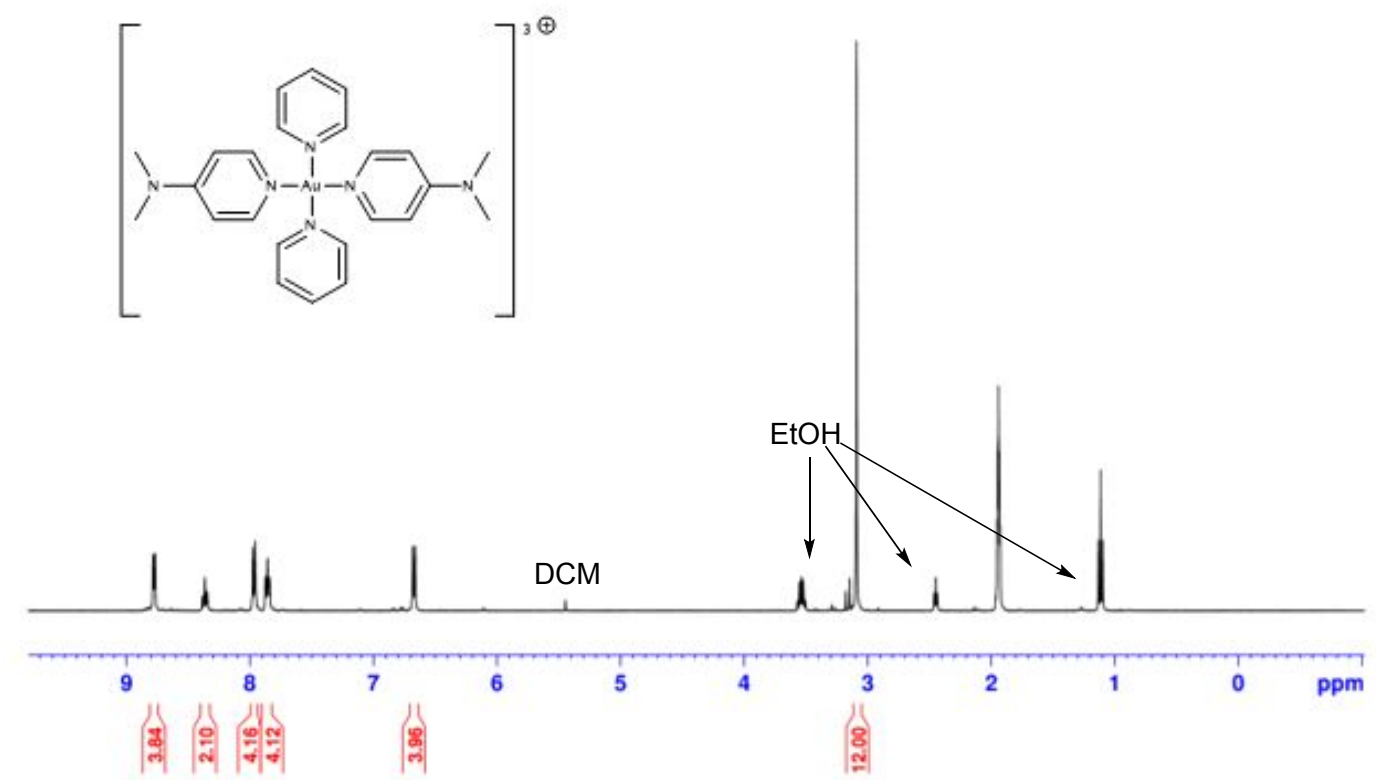


Figure S14. ${ }^{1} \mathrm{H}$ NMR of $8 \mathrm{H}$ from reaction between 6DMAP and $7 \mathrm{H}$.

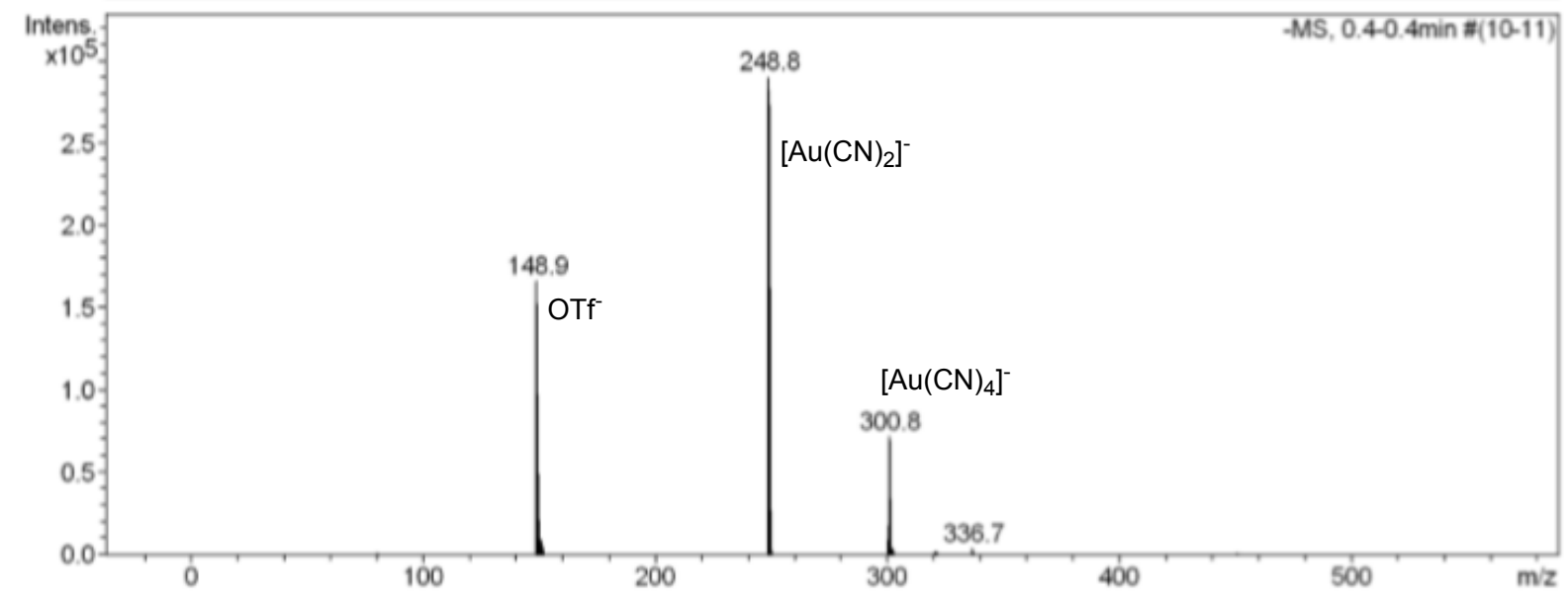

Figure S15. ESI-MS of $\left[\mathrm{Au}(\mathrm{CN})_{4}\right]^{-}$from reaction of 6DMAP and TMS-CN

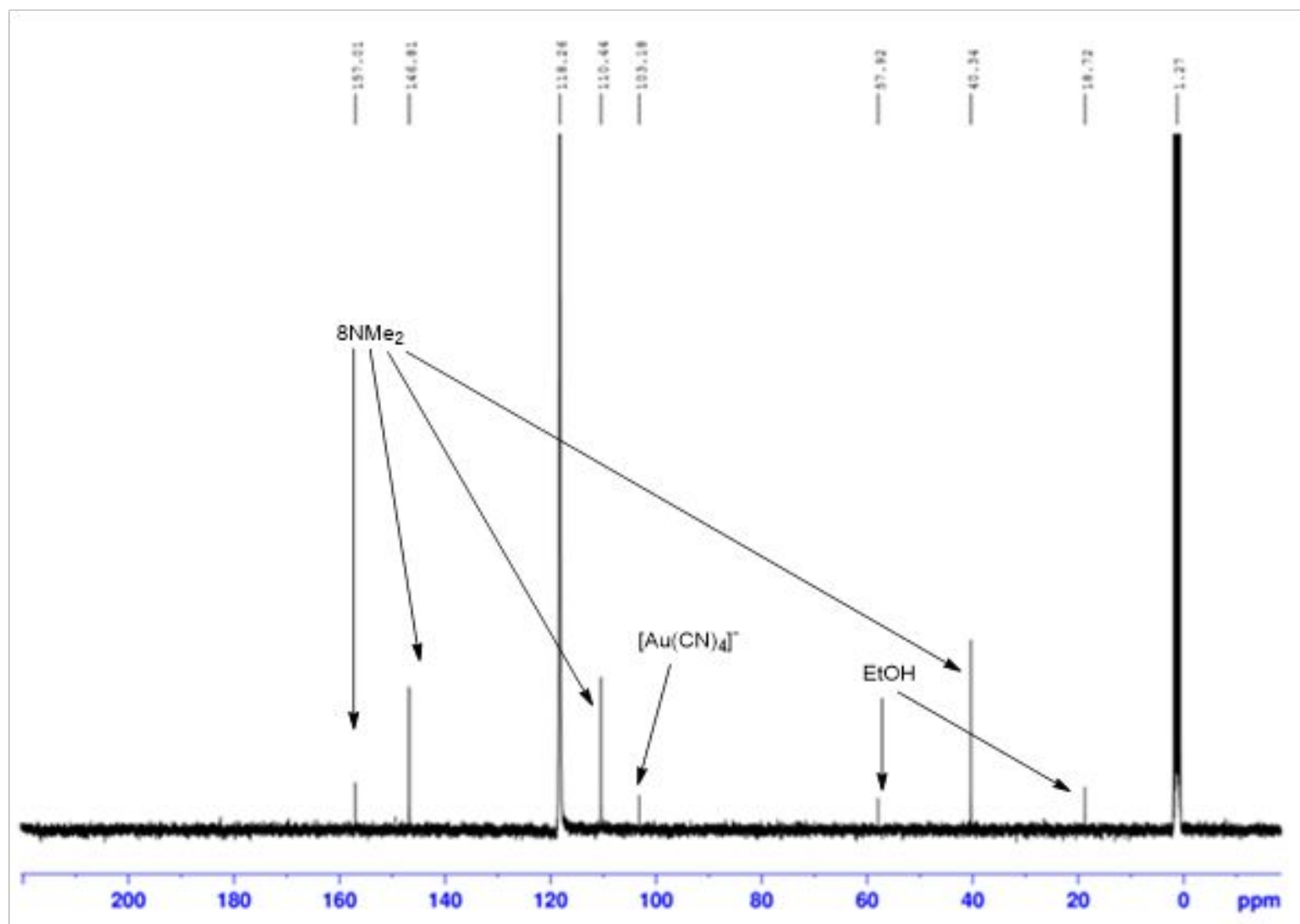

Figure S16. ${ }^{13} \mathrm{C}$ NMR of $8 \mathrm{NMe}_{2}$ and $\left[\mathrm{Au}(\mathrm{CN})_{4}\right]^{-}$from reaction of $6 \mathrm{DMAP}$ and TMS-CN, 


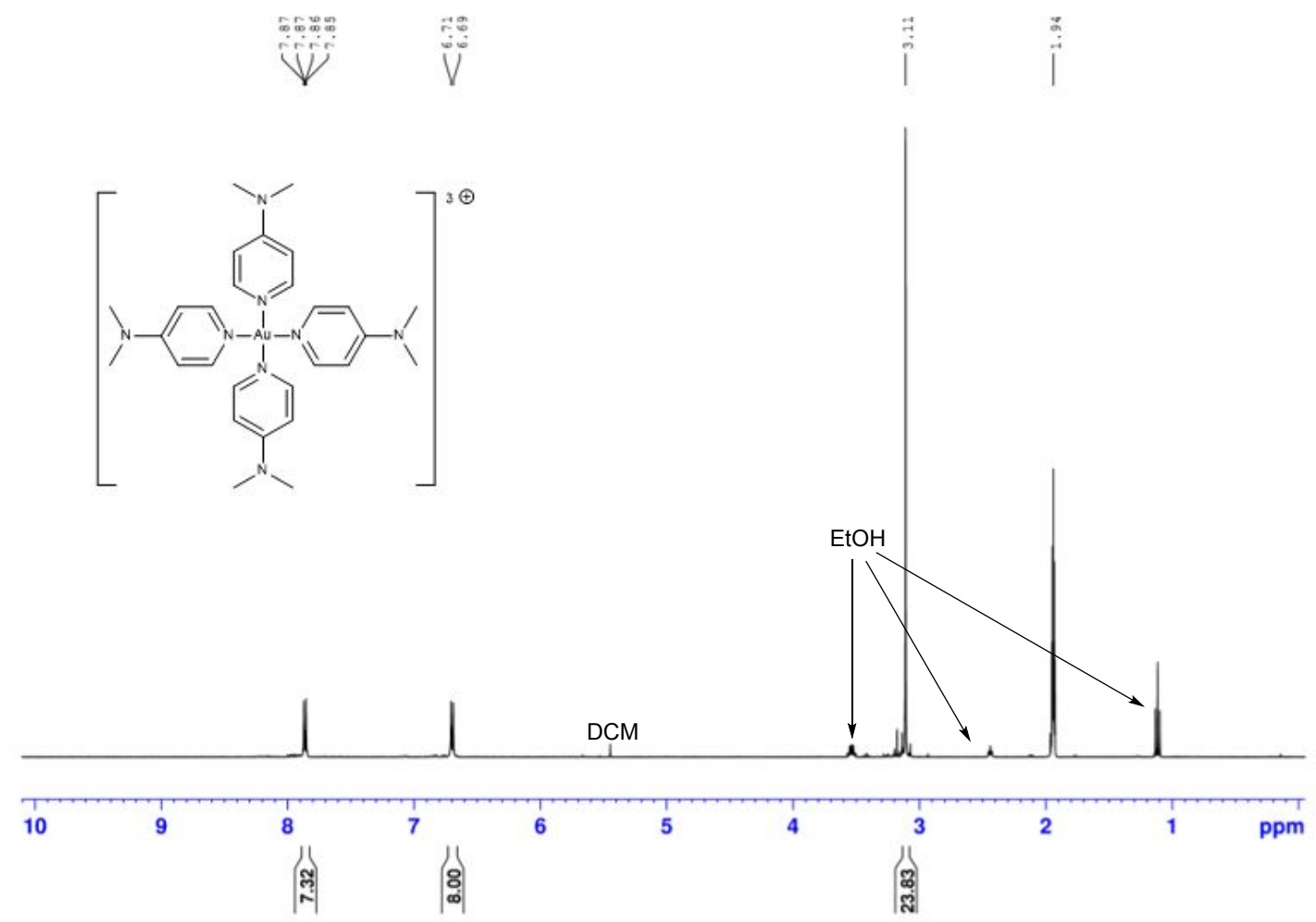

Figure S17. ${ }^{1} \mathrm{H}$ NMR of $\mathbf{8 N M e _ { 2 }}$ from reaction of 6 DMAP and TMS-CN,

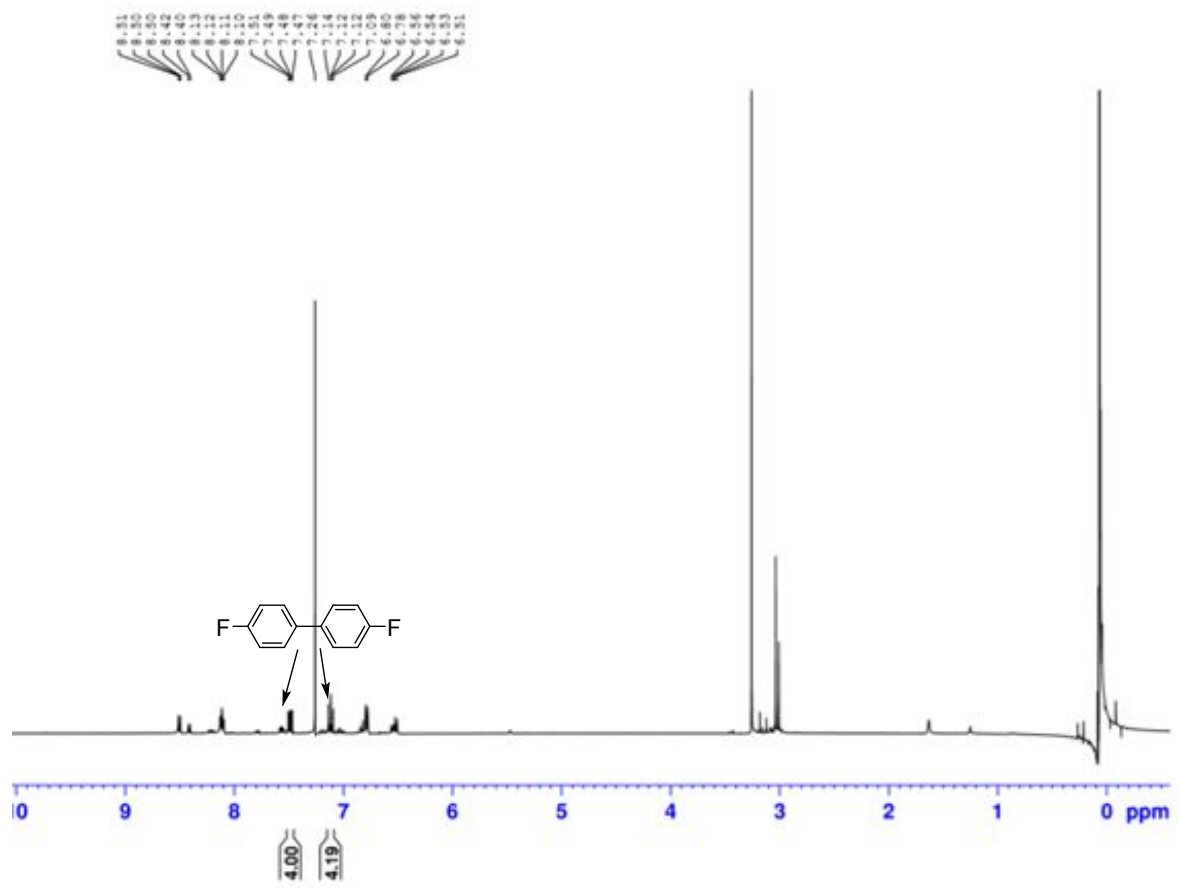

Figure S18. ${ }^{1} \mathrm{H}$ NMR of crude reaction between 4-fluorophenylboronic acid and 6DMAP. 


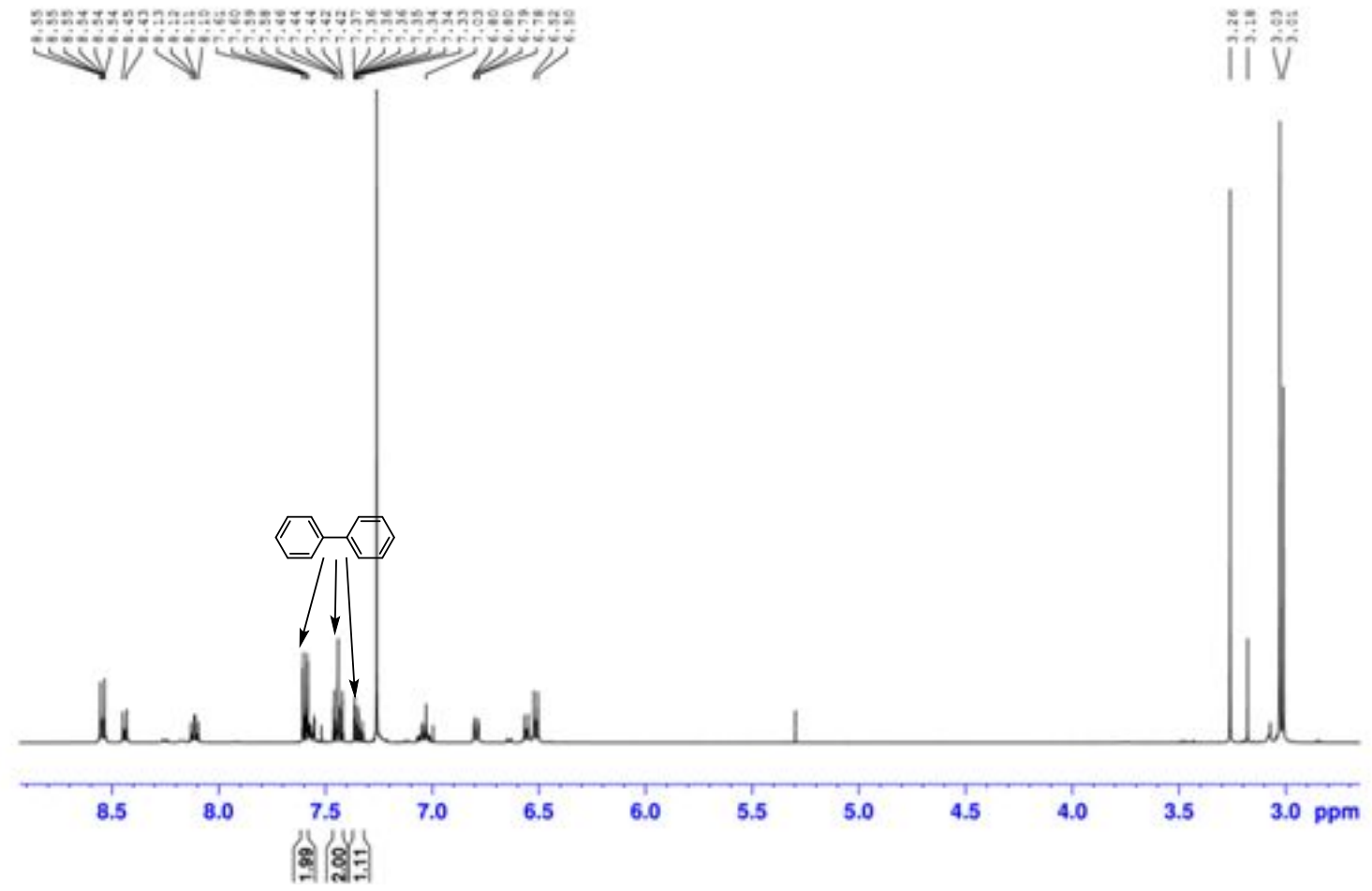

Figure S19. ${ }^{1} \mathrm{H}$ NMR of crude reaction between phenylboronic acid and 6DMAP.

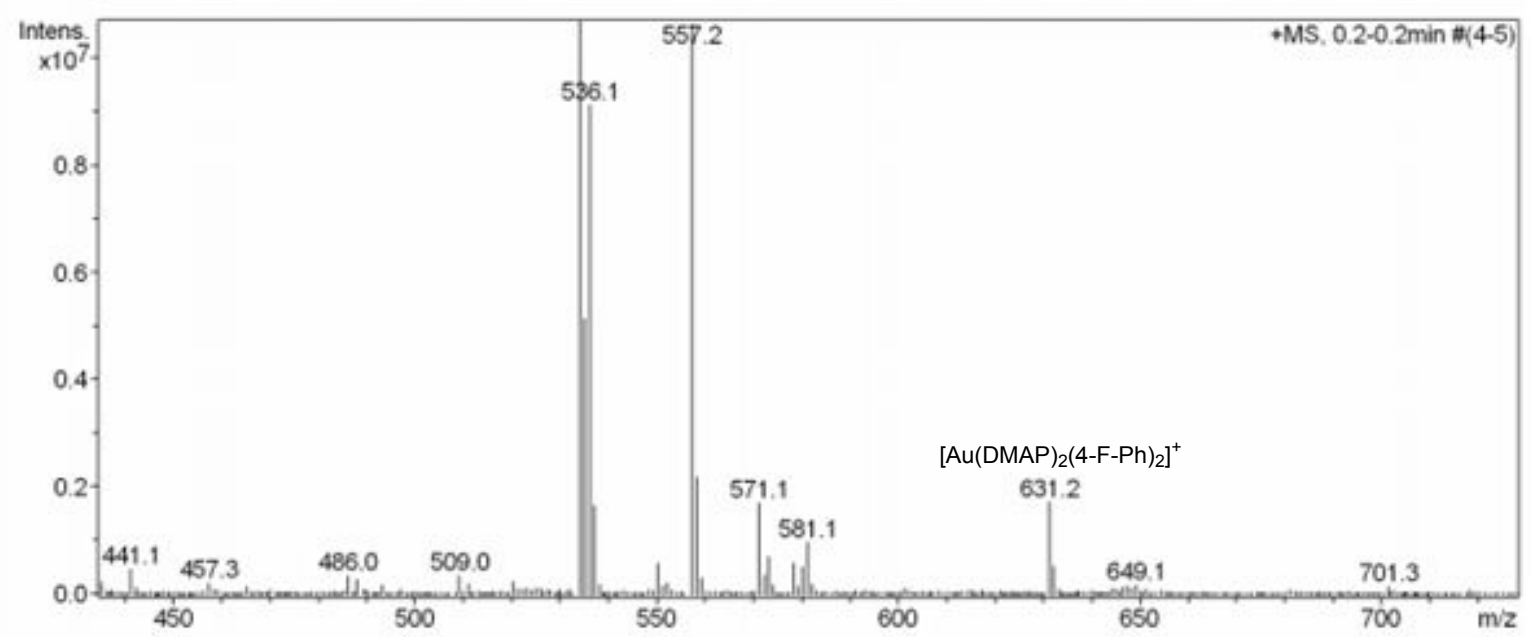

Figure S20. ESI-MS of 4-fluorophenylboronic acid and 6DMAP providing evidence for diarylated species. Calculated mass: 631.19, Obtained mass: 631.2. 


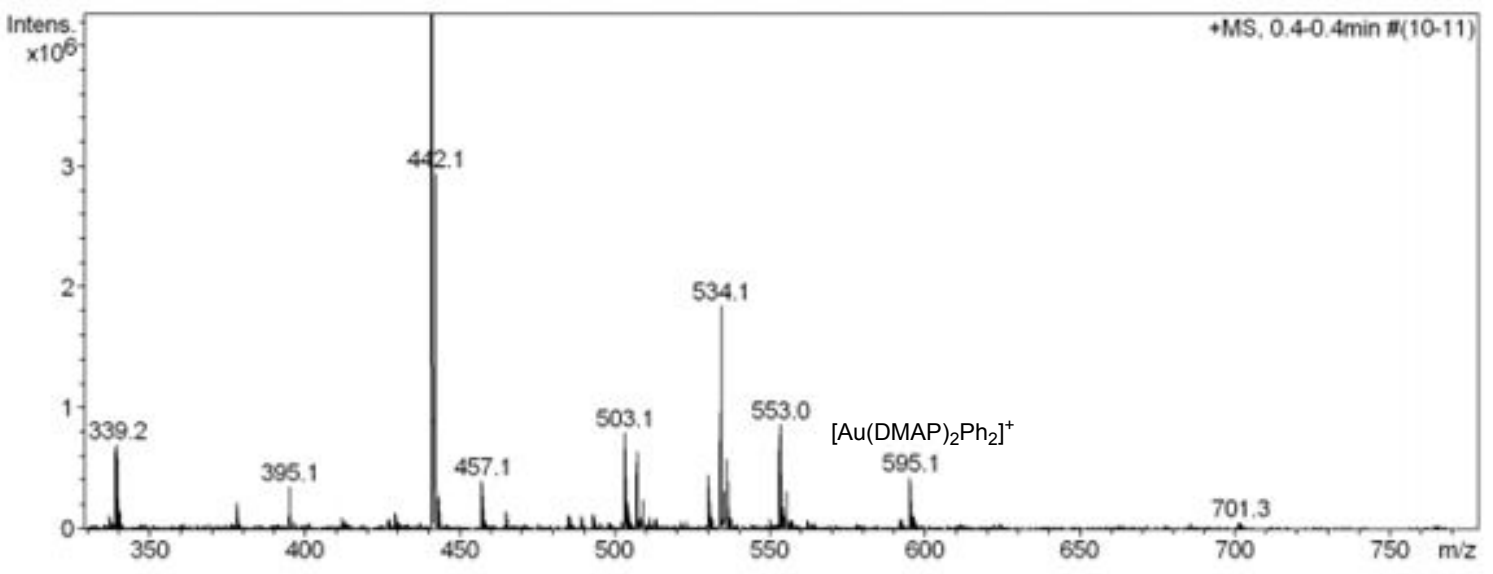

Figure S21. ESI-MS of reaction between phenylboronic acid and 6DMAP providing evidence for diarylated species. Calculated mass: 595.4, Obtained mass: 595.1. 